\title{
Auctions WHEN BidDERS PREPARE BY INVESTING IN IDEAS ${ }^{1}$
}

\author{
THOMAS D. JEITSCHKO \\ Dept. of Economics \\ Texas A\&M University \\ College Station \\ Texas 77843 \\ U.S.A. \\ thosd@econ.tamu.edu
}

\author{
ELMAR WOLFSTETTER \\ Dept. of Economics \\ Humboldt Universität zu Berlin \\ Spandauer Str. 1 \\ 10178 Berlin \\ Germany \\ wolf@wiwi.hu-berlin.de
}

August 1999

${ }^{1}$ Financial support was received by the Deutsche Forschungsgemeinschaft, SFB 373 ("Quantifikation und Simulation Ökonomischer Prozesse”), HumboldtUniversität zu Berlin. 


\begin{abstract}
We consider auction games where, prior to the auction, bidders spend resources to increase their valuations. The market game is solved by solving an equivalent auxiliary social choice problem. We show that standard auctions are fully efficient, whereas reserve price requirements entail a double inefficiency. Moreover, we explain how optimal auctions differ from the well-known static optimum, and sketch the impact of information spillovers.
\end{abstract}

JEL classifications: D 44.

Keywords: Auctions, Procurement. 


\section{Introduction}

In many auction settings bidders not only compete for the allocation of a given good at given valuations, but they also spend substantial resources to increase their valuations. For example:

$\triangleright$ Contractors engage in research and development in order to lower their cost or to be able to supply goods with more desirable quality characteristics.

$\triangleright$ Bidders for real estate property employ architects to create innovative plans to remodel buildings in order to more accurately assess their potential rental value.

$\triangleright$ Bidders for spectrum licenses invest in transmission technology, retail networks, and communication services in order to increase the value of radio frequencies.

The present paper contributes to analyzing the interrelationship between auctions and investment in a simple private values framework, assuming investments are made prior to bidding and are not observed by rival bidders.

There is a small literature on investment and bidding, mainly in the context of regulation (see the survey in Laffont and Tirole (1993), Ch. 7). While most contributions focus on investments that take place after the winner has been selected, Piccione and Tan (1996) consider investment in R\&D before procurement takes place, and independently model the impact of investments on costs essentially in the same way as we do here.

The plan of the paper is as follows. We state the model (Section 2), state and solve an auxiliary social choice problem (Sections 3), and use it to solve and the market game (Section 4). Then, we spell out how optimal auctions deviate from the well-known static optimum (Section 5), sketch how results change if investment is subject to information spillovers (Section 6), and close with a discussion.

\section{The Model}

There are $n \geq 2$ risk neutral bidders who compete for an indivisible good in an auction. Bidders' have independent private valuations, $V$, drawn from a fixed support that is normalized to $[0,1]$. The auctioneer's own valuation is equal to zero. If the auctioneer requires a reserve 
price above his own valuation, bidders do not participate below a certain critical valuation $v_{0} \in[0,1]$ (see Riley and Samuelson (1981)).

The market game is structured as follows: The auctioneer commits to an auction rule that awards the item to the highest bidder, subject to some reserve price requirement. After observing these rules, each bidder chooses his investment expenditure $a$ which shifts the probability distribution of that bidder's valuation, $F(v, a)$, and makes high valuations more likely. After investments are made, each bidder draws his valuation from $F$, and then makes his bid. Bidders do not observe each other's investment expenditures. Finally, the auction awards the item to the highest bidder subject to a reserve price requirement.

The investment technology has the following properties: 1) Investment implies a first-order stochastic dominance shift of the own probability distribution: ${ }^{1} \forall v, \forall a: F_{a}(v, a)<0$. 2) Investment is subject to diminishing returns to scale, in the sense of the "convexity of the distribution function condition:" $\forall a: F_{a a}(v, a)>0$.

3) The probability distribution of the highest order statistic from a sample of $n$ independently drawn valuations, $V_{(n)}, \mathcal{F}_{(n)}\left(v, a_{1}, \ldots, a_{n}\right)$, is strictly concave in investments. This assures that uniform investments are desirable. 4) For all $v: \lim _{a \rightarrow \infty} \mathcal{F}_{a}(v, a, \ldots, a)=0$. This assures that it pays to engage in some investment. 5) The hazard rate $f(v) /(1-F(v)$ is monotone increasing (Myerson's (1981) "regular case").

\section{Socially Optimal Investments}

To prepare the solution of the market game we construct an equivalent auxiliary social choice problem. The welfare optimum is obtained as a special case.

Suppose a social planner chooses investments $a:=\left(a_{1}, \ldots, a_{n}\right)$ to maximize the "as-if social surplus"

$$
S\left(v_{0}, a\right):=E_{V_{(n)} \geq v_{0}}\left[V_{(n)} \mid a\right]-\sum_{i} a_{i}+v_{0} \mathcal{F}_{(n)}\left(v_{0}, a\right)
$$

Evidently, $S$ is the social surplus from awarding the object to the bidder with the highest valuation if the auctioneer's own valuation is equal to $v_{0}$. However, the seller's valuation is equal to zero. Therefore, welfare maximization is obtained only for $v_{0}=0$. We denote the as-if welfare maximizer by $a^{*}\left(v_{0}\right)$ and the true welfare maximizer by $a^{*}(0)$.

\footnotetext{
${ }^{1}$ A function with a subscript denotes a partial derivative with respect to the subscripted variable.
} 
PROPOSITION 1 (AS-IF WELFARE MAXIMUM) The solution of the as-if welfare maximization problem is symmetric, unique, and positive unless $v_{0}$ is "large." Moreover, $a^{*}\left(v_{0}\right)$ is strict monotone decreasing if $a^{*}\left(v_{0}\right)>0$, and $a^{*}(0)>0$.

PROOF As one can easily verify, $S\left(v_{0}, a_{1}, \ldots, a_{n}\right)$ is strictly concave in investment expenditures, by the strict convexity of $\mathcal{F}_{(n)}\left(v, a_{1}, \ldots, a_{n}\right)$. Hence, if a solution exists, it must be unique. Suppose the solution were asymmetric. Then, any reassignment of optimal investment expenditures across bidders is also a solution, since all bidders have the same investment technology. Therefore, if a solution exists, it is symmetric. Hence, $\mathcal{F}_{(n)}\left(v, a_{1}, \ldots, a_{n}\right)=F(v, a)^{n}$, and with slight abuse of notation

$$
\begin{aligned}
S\left(v_{0}, a\right) & =\int_{v_{0}}^{1} v d F(v, a)^{n}-n a+v_{0} F\left(v_{0}, a\right)^{n} \\
& =1-\int_{v_{0}}^{1} F(v, a)^{n} d v-n a
\end{aligned}
$$

which gives rise to the Kuhn-Tucker conditions

$$
\begin{gathered}
S_{a}\left(v_{0}, a^{*}\right) \leq 0 \text { and } a^{*} S_{a}\left(v_{0}, a^{*}\right)=0 \\
S_{a}\left(v_{0}, a^{*}\right)=n\left(-\int_{v_{0}}^{1}\left(F\left(v, a^{*}\right)\right)^{n-1} F_{a}\left(v, a^{*}\right) d v-1\right)
\end{gathered}
$$

If no solution exists, $S\left(v_{0}, a\right)$ must be strictly monotone increasing in $a$. However, as one can easily show, this contradicts assumption 4). Therefore $S_{a}\left(v_{0}, a\right)$ is either positive for small $a$ and negative for large $a$ or nonpositive for all $a$.

Using assumption 4) it follows that $a^{*}(0)>0$. As one increases $v_{0}$, the $S_{a}^{*}$ function shifts down. Therefore, $a^{*}$ is a decreasing function of $v_{0}$. If $v_{0}$ is sufficiently large, $S_{a}\left(v_{0}, a\right)$ becomes negative, which entails the corner solution $a^{*}\left(v_{0}\right)=0$.

We mention that it is not socially optimal to restrict the number of participating investors/bidders. This follows immediately from the fact that the solution is symmetric for all $n$.

\section{Equilibrium Investments}

We now turn to the market game where bidders independently choose their investment expenditures, draw their private values, and make their bids. Remarkably, we find: 
PROPOSITION 2 (MARKET GAME) The solution of the market game, $\bar{a}\left(v_{0}\right)$, coincides with the solution of the "as-if welfare maximum", $\bar{a}\left(v_{0}\right)=a^{*}\left(v_{0}\right)$. Moreover, the market game implements the efficient allocation of the good and of investments (full efficiency) iff $v_{0}=0$.

ProOF Suppose every bidder assumes that all rival bidders have chosen the same investment level $\bar{a}$. Then, by a standard result from auction theory, the equilibrium payoff of a bidder with valuation $v \geq v_{0}$ from participating in the auction is

$$
u(v, \bar{a})=\int_{v_{0}}^{v} F(y, \bar{a})^{n-1} d y,
$$

and zero otherwise. Therefore bidders' ex ante expected payoff when choosing the investment expenditure $a$ can be written as follows (using integration by parts)

$$
\begin{aligned}
U(a, \bar{a}): & =E_{V \geq v_{0}}[u(V, \bar{a})]-a \\
& =\int_{v_{0}}^{1}(1-F(v, a)) F(v, \bar{a})^{n-1} d v-a
\end{aligned}
$$

A symmetric equilibrium exists if and only if $\bar{a}$ is a mutual best reply: $\bar{a}=\arg \max _{a} U(a, \bar{a})$. Since $F_{a}<0, F_{a a}>0$ the function $U(a, \bar{a})$ is strictly concave, and therefore the symmetric equilibrium investment expenditure $\bar{a}$ has to solve the conditions

$$
\begin{gathered}
U_{a}(\bar{a}, \bar{a}) \leq 0 \text { and } \bar{a} U_{a}(\bar{a}, \bar{a})=0 \\
U_{a}(a, \bar{a})=-\int_{v_{0}}^{1} F_{a}(v, a) F(v, \bar{a})^{n-1} d v-1 .
\end{gathered}
$$

Evidently, these conditions are equivalent to the Kuhn-Tucker conditions that characterize the "as-if welfare maximizer" $a^{*}\left(v_{0}\right)$ (see (3)-(4)). Therefore $\bar{a}\left(v_{0}\right)=a^{*}\left(v_{0}\right)$.

COROLLARY 1 (DOUBLE INEFFICIENCY) Suppose the auctioneer requires a reserve price above his own valuation, $v_{0}>0$. Then, bidders underinvest: $v_{0}>0 \Rightarrow \bar{a}\left(v_{0}\right)<a^{*}(0)$, and the allocation of the good is inefficient.

ProOF It is well-known that $v_{0}>0$ implies an inefficient allocation of the good. By Proposition $2 \bar{a}\left(v_{0}\right)=a^{*}\left(v_{0}\right)$ and by Proposition $1 \bar{a}\left(v_{0}\right)<$ $a^{*}(0)$. 


\section{Investment Incentives and Optimal Auctions}

The static optimal auction involves a reserve price requirement $v_{0}^{s}$ that solves the condition $\partial \pi / \partial v_{0}=0$ (Myerson (1981) and Riley and Samuelson (1981)). However, as one takes into account the effect of the reserve price on investment incentives, the optimal auction differs.

Proposition 3 (Optimal Auction) Compared to the static optimum the optimal auction involves a lower reserve price requirement.

ProOF Let $\pi\left(v_{0}, \bar{a}\left(v_{0}\right)\right)$ denote the auctioneer's equilibrium expected revenue. For given investment expenditures the static optimal reserve price, $v_{0}^{s}$, solves the condition $\partial \pi / \partial v_{0}=0$. However, accounting for the effect of $v_{0}$ on investments, one obtains

$$
v_{0}=v_{0}^{s} \Rightarrow \quad \frac{d \pi}{d v_{0}}=\frac{\partial \pi}{\partial v_{0}}+\frac{\partial \pi}{\partial \bar{a}} \bar{a}^{\prime}=\frac{\partial \pi}{\partial \bar{a}} \bar{a}^{\prime} .
$$

We now show that $d \pi / d v_{0}$ is negative at $v_{0}=v_{0}^{s}$.

By Proposition $1 \bar{a}^{\prime}\left(v_{0}\right)<0$. Therefore, it only remains to be shown that $\partial \pi / \partial \bar{a}$ is positive at $\left(v_{0}^{s}, \bar{a}\left(v_{0}^{s}\right)\right.$. By the Revenue Equivalence Theorem the auctioneer's expected revenue is the same as in a second-price auction, which is equal to (where all probabilities and expected values are conditional on $a=\bar{a}\left(v_{0}\right)$ )

$$
\begin{aligned}
\pi\left(v_{0}, \bar{a}\left(v_{0}\right)\right)= & v_{0}\left(1-\operatorname{Pr}\left\{V_{(n-1)}>v_{0}\right\}-\operatorname{Pr}\left\{V_{(n)}<v_{0}\right\}\right) \\
& +E\left[V_{(n-1)} \mid V_{(n-1)}>v_{0}\right] \operatorname{Pr}\left\{V_{(n-1)}>v_{0}\right\} \\
= & v_{0}\left(1-\operatorname{Pr}\left\{V_{(n)}<v_{0}\right\}\right) \\
& +\left(E\left[V_{(n-1)} \mid V_{(n-1)}>v_{0}\right]-v_{0}\right) \operatorname{Pr}\left\{V_{(n-1)}>v_{0}\right\} .
\end{aligned}
$$

Evidently, both terms on the RHS of this equation are strictly increasing in $\bar{a}$. Hence, $d \pi / d v_{0}<0$, and the revenue maximizing auctioneer should set $v_{0}$ below $v_{0}^{s}$.

\section{Information Spillovers}

Now suppose investment is subject to information spillovers. In particular, we stipulate that spillovers put this investor in the same position as if he had invested the amount $a+\lambda \tilde{a}$, where $\tilde{a}$ is the amount invested by his rivals. The spillover parameter is restricted to $\lambda \in[0, n-1]$, where $\lambda=n-1$ represents "complete spillovers" and $\lambda=0$ "no spillovers".

Spillovers reduce investment incentives. Not surprisingly, this implies: 
PROPOSITION 4 In the presence of information spillovers bidders invest less. Underinvestment occurs even if the auctioneer does not use a reserve price requirement, and the optimal auction involves an even lower reserve price requirement than in the absence of spillovers.

The proof of these results is a straightforward extensions of the above analysis.

\section{Discussion}

A critical ingredient of the present analysis is the concavity of the investment technology. This assumption makes it desirable that all bidders engage in the same level of investment expenditures. If, instead, investment is subject to increasing returns to scale, it becomes desirable to concentrate investments, and the market game has asymmetric solutions, where bidders draw their valuations from different distributions.

Asymmetric auctions are generally not tractable with analytic methods (see Maskin and Riley (1996)). However, the optimal asymmetric auction problem has been solved for given distributions by Myerson (1981). In the assumed "regular" case, when hazard rates are monotone increasing, the static optimal auction involves handicapping the bidder who draw his valuation from the more favorable distribution. This handicapping has an adverse effect on investment since it effectively penalizes the bidder who bears the main burden of investment. This suggests that, taking investment incentives into account, the optimal auction involves less handicapping, possibly to the extent of a preference for the bidder with the more favorable distribution.

\section{References}

Laffont, J. J., and Tirole, J. (1993). A Theory of Incentives in Procurement and Regulation. MIT Press.

Maskin, E., and Riley, J. G. (1996). Asymmetric auctions (Working Paper). Harvard University.

Myerson, R. B. (1981). Optimal auction design. Mathematics of Operations Research, 6, 58-73. 
Piccione, M., and Tan, G. (1996). Cost-reducing investment, optimal procurement and implementation by auctions. International Economic Review, 37, 662-685.

Riley, J. G., and Samuelson, W. F. (1981). Optimal auctions. American Economic Review, 71, 381-392. 